\title{
Economic policy uncertainty index and economic activity: what causes what?
}

\author{
Mirjana Čižmešija ${ }^{1}$, Ivana Lolić ${ }^{1, \dagger}$ and Petar Sorić ${ }^{1}$ \\ ${ }^{1}$ Department of Statistics, Faculty of Economics and Business, University of Zagreb, \\ J. F. Kennedy sq.6, 10000 Zagreb, Croatia \\ E-mail: 〈\{mcizmesija, ilolic, psoric\}@efzg.hr $\rangle$
}

\begin{abstract}
This paper is a follow-up on the Economic Policy Uncertainty (EPU) index, developed in 2011 by Baker, Bloom, and Davis. The principal idea of the EPU index is to quantify the level of uncertainty in an economic system, based on three separate pillars: news media, number of federal tax code provisions expiring in the following years, and disagreement amongst professional forecasters on future tendencies of relevant macroeconomic variables. Although the original EPU index was designed and published for the US economy, it had instantly caught the attention of numerous academics and was rapidly introduced in 15 countries worldwide. Extensive academic debate has been triggered on the importance of economic uncertainty relating to the intensity and persistence of the recent crisis. Despite the intensive (mostly politically-motivated) debate, formal scientific confirmation of causality running from the EPU index to economic activity has not followed. Moreover, empirical literature has completely failed to conduct formal econometric testing of the Granger causality between the two mentioned phenomena. This paper provides an estimation of the Toda-Yamamoto causality test between the EPU index and economic activity in the USA and several European countries. The results do not provide a general conclusion: causality seems to run in both directions only for the USA, while only in one direction for France and Germany. Having taken into account the Great Recession of 2008, the main result does not change, therefore casting doubt on the index methodology and overall media bias.
\end{abstract}

Keywords: Economic Policy Uncertainty Index, Granger causality, economic uncertainty

Received: September 30, 2016; accepted: December 08, 2017; available online: December 30,2017

DOI: $10.17535 /$ crorr.2017.0036

\section{Introduction}

Economic uncertainty reflects the difficulty to identify possible future outcomes and their probabilities, or simply fear of the unknown. By nature, it is a latent variable (based on its theoretical properties). It is unobservable and directly

\footnotetext{
$\dagger$ Corresponding author
} 
immeasurable, which has led to numerous different attempts at measuring its fluctuations. Typical proxies are stock market volatility, other volatility indicators (based on estimates from GARCH models), and disagreement between the perceptions and expectations of economic agents (based on consumers' disagreeement). In the last five years, there have been several other attempts at measuring uncertainty fluctuations. The Economic Policy Uncertainty Index (EPU) is a newly formed uncertainty measure developed by American researchers S. R. Baker (Northwestern University), N. Bloom (Stanford University), and S. J. Davis (University of Chicago).

Changes in economic uncertainty are driven by all kinds of different sources: economic recessions, wars, natural disasters, political campaigns, elections, legislation changes, etc. Some of these are inevitable, whereas others are controllable and partly addressable by policyholders. A lack of information about current events and policy actions could cause uncertainty about future outcomes for businesses and households. This highlights the fact that proper communication is essential in mitigating uncertainty increases. A significant part of recent economic literature has focused on examining different communication strategies for monetary policy. It has indicated that communication is a powerful tool for the central bank and may assist in achieving macroeconomic objectives [6]. To the best of our knowledge, analysis of communication strategies for fiscal policyholders has not gained traction in the academic community.

Communication by policyholders mostly consists of press conferences, interviews, and official statements communicated to the broader public through TV, radio, and newspaper coverage (via articles on websites or newspaper print). This has led to a completely new field of measurement in social sciences, using text-search procedures on newspaper databases for measuring a specific certain phenomenon. The newly recognized idea is that 'measuring' something in articles published on selected websites may indeed reflect changes in the economic policy uncertainty. This is the concept that the authors of the EPU index are addressing.

The EPU index focuses solely on identifying uncertainty stemming from both fiscal and monetary policy actions. It is a pioneering attempt at measuring policy uncertainty based on media coverage of uncertainty in newspaper articles that cover topics that supposedly raise the level of uncertainty. The main idea behind the EPU index is quite straightforward: uncertainty increases when media coverage of economic uncertainty increases. The authors have devised a textsearch procedure that calculates the proportion of articles that contain specific keywords. An EPU article needs to have at least one word from each of the following three groups: Economic ("economic" or "economy"), Policy ("congress", "deficit", "Federal Reserve", "legislation", "regulation" or "White House"), and Uncertainty ("uncertain" and "uncertainty"). However, attaching all the weight solely on a single information source increases the possibility of bias, hence the index consists of two additional parts: the number of federal tax code provisions 
expiring in the next10 years and disagreement amongst professional forecasters on the future tendencies of relevant macroeconomic variables.

Theoretical macroeconomic and microeconomic literature suggests a significant impact of uncertainty on the behavior of economic agents using the "wait-andsee" channel. The main characteristic of agent behavior during uncertain times is delaying all irreversible and high-cost decisions. Managers delay new hiring and investments, while consumers cut back on spending and increase their savings. All this reflects a decrease of aggregate economic activity and, consequently, lowers real GDP growth. However, the causality relationship is not that clear, given that uncertainty increases as a recession deepens. This issue has been investigated in several scholarly papers, but not been treated with a formal econometric causality test.

This paper is organized as follows: Section 2 discusses the index methodology and its relationship to GDP growth and economic activity, Section 3 provides a brief description of causality tests, Section 4 summarizes the obtained results, and Section 5 provides conclusions and remarks.

\section{Economic Policy Uncertainty Index}

The EPU index is a composite indicator consisting of three parts based on distinctive source types: newspaper coverage, legislation changes, and the Survey of Professional Forecasters (SPF).

\subsection{Index methodology}

The largest weight is assigned to newspaper coverage of policy-related economic uncertainty $(1 / 2)$, while the other two parts have smaller importance (legislation changes $1 / 6$ and SPF 1/3). These other two parts have been added to the index to reduce potential bias and enrich the underlying information set.

The EPU's fundamental component is an index of search results from 10 large newspapers: USA Today, Miami Herald, Chicago Tribune, Washington Post, Los Angeles Times, Boston Globe, San Francisco Chronicle, Dallas Morning News, New York Times, and the Wall Street Journal. This part is based on the frequency of articles that mention selected keywords from three groups of words: economic, policy, and uncertainty. These frequencies are calculated for each newspaper, then scaled by the total amount of published articles in each month, and finally normalized. The algorithm is elucidated using the following formulas:

1. Calculate $\sigma_{i}=$ standard deviation of $X_{i t}$ for the interval from 1985 to 2009 for each newspaper 
2. Relative frequency $Y_{i t}=\frac{X_{i t}}{\sigma_{i}}$

3. Average $Z_{t}=\frac{1}{10} \sum_{i=1}^{10} Y_{i t}$

4. Calculate $M=$ average of $Z_{t}$ for the interval from 1985 to 2009

5. Calculate newsEPU ${ }_{t}=\frac{Z_{t}}{M} 100$.

The second component of the indicator reflects policy uncertainty stemming from legislation changes through federal tax code provisions which are set to expire in the coming years. The third component of EPU index draws on the SPF from the Federal Reserve Bank of Philadelphia. The authors utilize the dispersion between individual forecaster predictions concerning future levels of important policyrelated macroeconomic variables, such as the Consumer Price Index, Federal Expenditures, and State and Local Expenditures. Using this dataset, the authors then calculate disagreement in forecasts among professionals, which yields the final part of the EPU index.

According to the derived values of the EPU (shown in Figure 1), it seems that the index has been picking up most of the important events in recent American economic history.

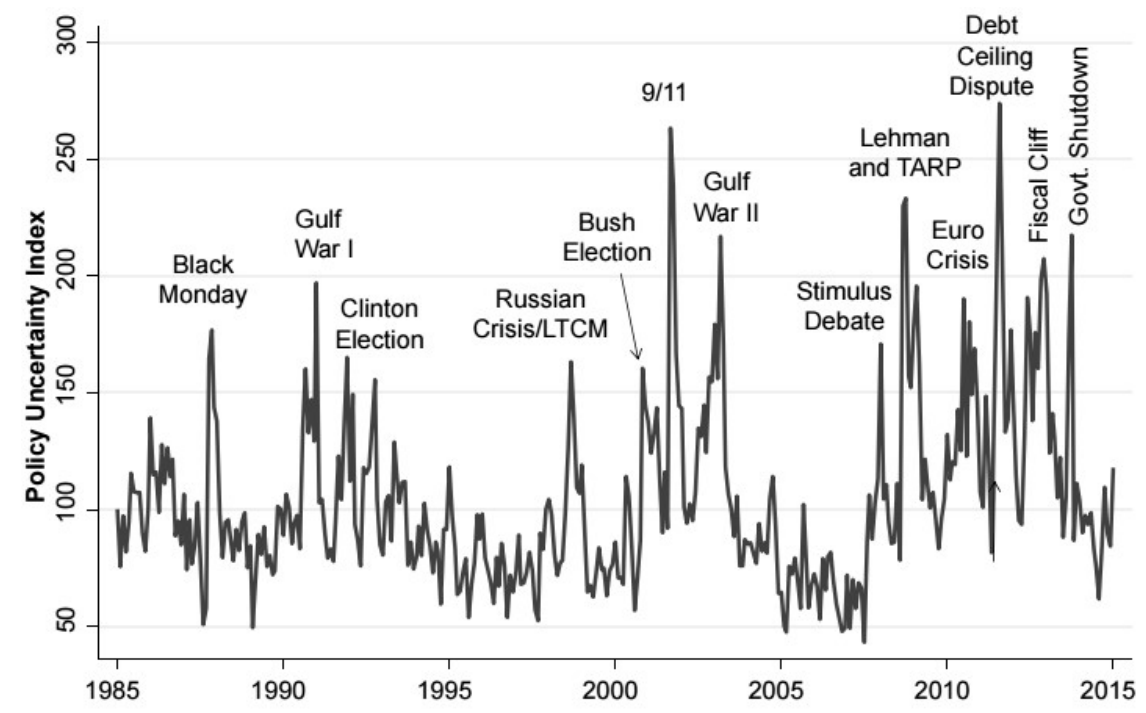

Figure 1: Economic Policy Uncertainty Index for the USA [4] 
The EPU index was first introduced in the US. Hence, its design incorporates several specificities of the US legal and economic structure. The newspaper coverage is augmented by the legislation component (tax code provisions) and SPF disagreement. However, these two components do not have similar equivalents in other countries due to different legal systems or relatively poor official statistics. Given that the authors' intention was to broaden their EPU index to other countries; they had to alter the methodology making it more widely applicable. The easiest approach was to focus solely on newspaper coverage. Hence, the monthly EPU index (consisting of only newspaper coverage) is now published for a total of 15 countries: USA, Canada, Europe, Germany, UK, Italy, France, Spain, Netherlands, China, India, Japan, Russia, South Korea, and Australia.

\subsection{Uncertainty and economic activity: theoretical aspects}

According to the theoretical economic discussions, uncertainty has a detrimental effect on the entire economic system [16, 23]. When faced with uncertainty, economic agents change their behavior and alter their decision making process (as shown in $[8,25])$. This is primarily evident in the "wait-and-see" strategy, leading to delaying all possible decisions. Agents postpone making irreversible decisions (especially those that include certain sunk costs) and wait until the development of future economic conditions becomes clearer. This type of behavior should ultimately reflect in almost every aggregate macroeconomic variable, such as investments, employment, or economic activity (GDP or e.g. industrial production).

Economic literature mainly explains this effect through concepts such as the Adjustment Cost (Real Option Effect) and Risk Aversion (Precautionary Savings). Decisions on investment, new hiring, and buying durable goods is a long-term decision that is not easily reverted. When a manager wants to withdraw from an investment decision, they are confronted by the costs of rearranging prepared resources such as financial assets, personnel, equipment, and the like. [10, 22]. Moreover, with every new hiring there are potential costs for a company if management decides to reduce the number of employees (headhunting costs, education, and compensation stipulated by the Labor Act [7]). On the other hand, when a consumer buys a durable good (e.g. a car or furniture), he can re-sell it only at a reduced price. These are the reasons why this channel is called Adjustment Cost because all decision makers are confronted with charges. In addition, this channel is called Real Option because all economic agents are able to make decisions regardless of whether the option to invest/hire/spend is utilized.

The second specific channel is called Risk Aversion or Precautionary Savings. Risk is a normal element of doing business and a manager's job description includes maneuvering through complex decisions. However, managers become risk averse 
under high uncertainty [13], hence investments and purchases of durable goods plummet. Consumers also become risk averse and exhibit precautionary behavior by increasing their savings [5].

In summarizing these mentioned theoretical considerations, the expectation is that economic uncertainty has a negative effect on aggregate economic activity. However, the time dynamics of the stated relationship is identified through empirical research.

\subsection{Literature review}

The relevant empirical literature offers an abundance of methodological approaches to measuring uncertainty, and an abundance of analytical tools to examine the relationship between uncertainty and economic activity. The stated interrelationship is thoroughly investigated within various econometric frameworks, such as linear regression, VAR, panel VAR, and structural VAR in [1, 2, $4,9,11,14]$. All of these papers conclude that uncertainty has a negative, weak, or significant impact on economic activity regardless of the choice of the uncertainty measure.

We will provide a few findings from these papers. Using VAR modelling, it has been shown that EPU positively feeds into the US stock market volatility [4]. In a similar way, it has been demonstrated that EPU's contribution to increasing volatility is considerably higher for government-related companies (health care, defense and the construction sector). On the macroeconomic level, this leads to lower investment, employment, and US industrial production [4]. Furthermore, EPU seems to generate rather accurate predictions of US recessions in the framework of probit models [15]. The effects of EPU shocks are not only restricted to the US, but also create considerable spillovers to the euro area [9].

The empirical result of a significant (but short-lived) effect of EPU on economic activity is all the more important given its corroboration by findings for other uncertainty proxies. For example, it has been shown that economic uncertainty negatively feeds into US industrial production and employment [14]. The authors of that study utilized a factor model to econometrically extract the underlying uncertainty from two extremely rich macroeconomic datasets for the US economy. Other papers mostly focus on employing forecasting disagreement as a proxy for economic uncertainty. Such literature has established that prognostic disagreement significantly reduces US industrial production, working hours, and employment [2]. These results seem to be more pronounced in the US than in Germany. A similar approach (utilizing SPF disagreement as a proxy for uncertainty) is also relevant for the euro area [1]. Forecasting disagreement (proxying uncertainty) has in a similar way been proven to account for as much as a quarter of the decline of UK industrial production during the 2008 recession [11]. 
It is necessary to highlight two distinctive points. First, the vast majority of these studies focus on the US economy (augmented by the euro area and Germany). However, the EPU index (as a proxy for economic uncertainty) is currently publicshed in a series of countries. This enables us to perform a multi-country analysis and compare the effects of EPU among these countries. Second, most of the stated studies have not formally taken into account the possible endogeneity bias of the issue involving Granger causality. Several authors have stressed that the question of causality is not resolved within their findings. See, e.g. [4]: "The second [approach] uses macro data in VAR analyses, capturing multiple channels of influence but offering weaker identification of causal effects". As pointed out, current scientific literature lacks strong evidence of causality between uncertainty and economic activity. The authors intend to shedd some light on the causality issue through adoption of statistical causality tests applicable to the examined variables.

\section{Causality test}

The dataset analyzed in this paper comprises the EPU index ${ }^{\ddagger}$ and the industrial production index (IND) $(2010=100)$ for the US and five EU economies (France, Germany, Italy, Spain, and the UK). The EPU index is obtained from www.policyuncertainty.com, while the International Monetary Fund (International Financial Statistics) is the source for industrial production data. All series are seasonally adjusted using the ARIMA X-12 method.

Industrial production is chosen as a proxy variable for total economic activity given that it is commonly found to cyclically follow GDP and many research papers use it to capture GDP dynamics (e.g. $[17,20]$ ). An additional reason for employing monthly industrial production instead of quarterly GDP is to preserve valuable degrees of freedom.

The time period of causality analysis is conditioned by the start of the EPU series for each country: January 1987 for the USA and France, January 1993 for Germany, January 1997 for Italy and the UK, and January 2001 for Spain. The end of the period is April 2016 for all countries.

Since EPU is conceptualized as a leading indicator, it would also be interesting to examine whether its predictive characteristics differ in various phases of the business cycle. With that in mind, the authors divided the examined period in two parts: before and after the start of the Great Recession in 2008. The cut-off point was set to September 2008, due to the Lehman Brothers bankruptcy, which

\footnotetext{
For consistent and comparable results, the authors used the same variant of the EPU (only newspaper coverage).
} 
has initiated a wide cause-and-effect chain and triggered the global recession. ${ }^{\S}$ Although the crisis obviously did not solely last till the end of the examined period (April 2016), the 2008-2016 period may be characterized as highly turbulent because of the concurrent political and economic instabilities (immigration crisis, US military interventions in the Middle East, uncertainty regarding Brexit and its economic consequences, etc.).

The most popular statistical test for investigating the causality issue is a Granger causality test. The main assumptions include strong restriction on the order of integration which needs to be zero. However, the majority of the respectively observed variables are integrated into an order of one ${ }^{* *}$, hence a standard Granger causality test provides spurious results. To circumvent this problem, the Toda and Yamamoto approach [27] is followed here.

The Toda and Yamamoto approach refers to causality testing in the presence of nonstationary variables. They propose to estimate an "augmented" VAR model to correct for the observed unit roots. In the bivariate case considered in this paper, the VAR setup has the following form:

$$
\begin{aligned}
& E P U_{t}=a_{1}+\sum_{i=1}^{p+d} \beta_{1, i} E P U_{t-i}+\sum_{j=1}^{p+d} \gamma_{1, j} I N D_{t-j}+\varepsilon_{1, t} \\
& I N D_{t}=a_{2}+\sum_{i=1}^{p+d} \beta_{2, i} I N D_{t-i}+\sum_{j=1}^{p+d} \gamma_{2, j} E P U_{t-j}+\varepsilon_{2, t}
\end{aligned}
$$

where $p$ is the optimal lag order chosen by information criteria (AIC in this study) $)^{\dagger \dagger}, d$ is the maximum order of integration of the observed time series ( $d=1$ in this study), $a_{1}$ and $a_{2}$ are constant terms, $\beta s$ and $\gamma s$ are autoregressive parameters, while $\varepsilon_{1 t}$ and $\varepsilon_{2 t}$ are white-noise (mutually uncorrelated) error terms. The causality testing procedure within the Toda and Yamamoto approach comes down to testing the following null hypotheses:

$$
\begin{gathered}
H_{0}: \text { IND does not Granger cause EPU if } \\
\gamma_{1,1}=\gamma_{1,2}=\ldots=\gamma_{1, p}=0
\end{gathered}
$$

\footnotetext{
$\S$ The authors also considered an alternative approach, i.e. employing an algorithm such as the Bry-Boschan procedure to date the business cycle turning points in each country. However, that would leave the authors with too few data points in some phases of the cycle for applying the causality testing procedure.

** The ADF test results are left out here due to space limitations, but can easily be obtained from the authors.

It In several cases, the authors have increased the lag length (in comparison to the one favored by AIC) to resolve autocorrelation issues (as suggested by the autocorrelation LM test).
} 


$$
\begin{gathered}
H_{0}: \text { EPU does not Granger cause IND if } \\
\gamma_{1,1}=\gamma_{1,2}=\ldots=\gamma_{1, p}=0 .
\end{gathered}
$$

Therefore, the non-causality null hypothesis is tested only on the first $p$ lags of the variables at hand.

\section{Results}

The hypotheses given in (3) are tested for the six analyzed countries. Moreover, the authors also scrutinize if the leading characteristics of EPU have changed during the 2008 recession. To shed some light on the potential time-variability of the observed relationship, Granger causality tests are carried out separately for the pre-crisis and crisis period. Table 1 summarizes the obtained causality test results. Table entries are the obtained p-values.

\begin{tabular}{|l|c|c|c|c|c|c|}
\hline \multirow{3}{*}{ Country } & \multicolumn{2}{|c|}{ Full period } & \multicolumn{2}{c|}{ Pre-crisis period } & \multicolumn{2}{c|}{ Crisis period } \\
\cline { 2 - 7 } & $\begin{array}{c}\text { IND } \rightarrow \\
\text { EPU }\end{array}$ & $\begin{array}{c}\text { EPU } \rightarrow \\
\text { IND }\end{array}$ & $\begin{array}{c}\text { IND } \rightarrow \\
\text { EPU }\end{array}$ & $\begin{array}{c}\text { EPU } \rightarrow \\
\text { IND }\end{array}$ & $\begin{array}{c}\text { IND } \rightarrow \\
\text { EPU }\end{array}$ & $\begin{array}{c}\text { EPU } \rightarrow \\
\text { IND }\end{array}$ \\
\hline France & 0.8507 & $\mathbf{0 . 0 8 7 3}$ & 0.7222 & $\mathbf{0 . 0 2 4 0}$ & $\mathbf{0 . 0 8 9 9}$ & 0.2733 \\
\hline Germany & $\mathbf{0 . 0 1 4 5}$ & 0.2622 & $\mathbf{0 . 0 0 0 9}$ & $\mathbf{0 . 0 6 3 6}$ & 0.3930 & 0.8149 \\
\hline Italy & 0.1597 & 0.9367 & 0.6419 & 0.4904 & 0.1486 & 0.8466 \\
\hline Spain & 0.7769 & 0.9818 & 0.7437 & 0.4434 & 0.3494 & 0.9203 \\
\hline UK & 0.5141 & 0.3189 & 0.3145 & 0.2374 & 0.6884 & 0.2598 \\
\hline USA & $\mathbf{0 . 0 4 8 3}$ & $\mathbf{0 . 0 0 6 8}$ & 0.6405 & $\mathbf{0 . 0 0 0 4}$ & 0.1179 & 0.3122 \\
\hline
\end{tabular}

Table 1: Causality test results

It is clear that the non-causality hypothesis cannot be rejected for the vast majority of countries and model specifications. Regarding the entire period, the EPU Granger causes IND at the 1\% significance level only in the USA (and at the 10\% level for France). Contradicting our starting assumption, the crisis period does not enhance the importance of the EPU because there are no signs of causality for any of the observed economies. However, the pre-2008 period seems to exhibit much more pronounced leading characteristics of the EPU index. The null hypothesis at conventional significance levels is rejected for France, Germany, and the USA.

Although there are no clear-cut patterns in the results obtained for the six respective economies, an interesting inference instantly becomes obvious from Table 1. Namely, empirical studies often reveal that psychological factors such as confidence or uncertainty grow in significance in turbulent economic times [24]. 
This is strongly contradicted by these obtained results. The EPU seems to perform better under stable macroeconomic conditions.

It is often found that media reports significantly feed into various sorts of economic phenomena, such as households' indebtedness [3], or inflation [12]. However, the influence of media reports on aggregate economic activity is still not firmly corroborated in the empirical literature. This study also goes in line with such conclusions. The bad leading characteristics of the EPU index can to some extent be explained by methodological flaws $[18,19]$, or by the widely recognized media bias [21].

Namely, the EPU index has attracted a lot of criticism. The loudest among comes from the Nobel Laureate Paul Krugman who repeatedly criticized the EPU, labeling it as the "Phony Fear Factor" in [18] and the "Uncertainty Scam" in [19]. The main downside of the index, according to critics, is its relying on newspaper coverage when it is clear that media reports exhibit considerable bias in favoring negative news (as shown in [21]). Moreover, critics accuse the authors of wrongly interpreting the index as a measure of uncertainty instead of viewing it as expectations or pessimism indicator. This discussion has stayed within the frame of blogosphere and newspaper reports, and in general lacks rigorous scientific evidence.

This by no means implies that the EPU cannot be used to explain or forecast economic activity. On the contrary, previous studies do provide considerable evidence in favor of the EPU's significance and utility $[4,9,15]$. However, it seems that the pure causal effect is somewhat weaker than what would be expected. This finding is quite in line with a similar study of the EPU's leading characteristics in 13 world countries [26]. One of the implications of this finding is that some of the critics regarding media data reliability, bias, and consistency were rightly pointed out. To counteract them, Baker, Bloom, and Davis have conducted a large-scale audit study of the US dataset. This has perhaps conditioned the result that the US EPU indeed does cause Granger-like economic activity (over the entire period and pre-crisis period). It should perhaps be useful to perform a similar analysis for all observed countries. That methodological step might improve the EPU's overall predictive accuracy.

\section{Conclusion}

This study provides an early effort to discern the true causality direction between the EPU index and aggregate economic activity. Opposing most of the existing studies on EPU (which do not properly take into account the endogeneity issue), we performed a formal econometric test of Granger causality between the EPU and economic activity in six developed economies. The results of the Toda and Yamamoto approach to causality testing demonstrate that there are only marginal causal effects in the observed relationship. The strongest evidence of causality is 
found in the USA, for which the EPU index is initially conceptualized and publicshed. On average, media reports on economic uncertainty seem not to have a significant causal effect on aggregate economic activity.

Quite unexpectedly, the strongest evidence of causality is found in the pre-crisis period. This striking finding contradicts the existing empirical evidence on the growing significance of psychological factors in governing economic activity during abrupt recessions. Such results can be interpreted in line with more accurate and objective media reports in times of economic well-being, while economic turbulences seem to encourage more biased media reports, resulting in their non-significant relationship with economic activity.

Of all the possible causes of such poor leading characteristics, Krugman's arguments on the EPU's potentially flawed methodology and overall media bias are certainly among the most plausible ones. Future studies should certainly entail a comparative sectoral analysis to shed some light on the way different economic sectors react to uncertainty within the system.

\section{Acknowledgement}

This work has been supported in part by the Croatian Science Foundation (under the project No. 3858) and University of Zagreb (research grant no. DP018, 2015/2016).

\section{References}

[1] Abel, J., Rich, R., Song, J., and Tracy, J. (2016). The Measurement and Behavior of Uncertainty: Evidence from the ECB Survey of Professional Forecasters. J. Appl. Econ., 31, 533-550.

[2] Bachmann, R., Elstner, S., and Sims, E. (2013). Uncertainty and economic activity: evidence from business survey data. American Economic Journal: Macroeconomics, 5(2), 217-49.

[3] Baker, M.J. and George, L.M. (2010). The role of television in household debt: evidence from the 1950's. B.E. Journal of Economic Analysis and Policy, 10(1), 1-38. DOI: 10.2202/1935-1682.2393

[4] Baker, S. R., Bloom, N., and Davis, S. J. (2016). Measuring economic policy uncertainty quarterly, Journal of Economics, 131 (4), 1593-1636.

[5] Bansal, R., and Yaron, A. (2004). Risks for the long run: a potential resolution of asset pricing puzzles. The Journal of Finance, 59(4), 1481-1509.

[6] Blinder, A. S., Ehrmann, M., Fratzscher, M., De Haan, J., and Jansen, D. J. (2008). Central bank communication and monetary policy: a survey of theory and evidence. Journal of Economic Literature, 46(4), 910-945.

[7] Bloom, N. (2009). The impact of uncertainty shocks. Econometrica, 77(3), 623-685. 
[8] Carroll, C. and Dunn W. (1997). "Unemployment expectations, jumping (s,S) triggers, and household balance sheets". In NBER Macroeconomics Annual 1997, Volume 12, NBER Chapters, pp. 165-230. National Bureau of Economic Research, Inc.

[9] Colombo, V. (2013). Economic Policy Uncertainty in the US: Does it matter for the Euro area. Economics Letters, 121(1), 39-42.

[10] Cooper, R. W., and Haltiwanger, J. C. (2006). On the Nature of Capital Adjustment Costs. Review of Economic Studies, 73(3), 611-33.

[11] Denis, S., and Kannan, P. (2013). The Impact of Uncertainty Shocks on the UK Economy (No. 13/66). International Monetary Fund.

[12] Dräger, L. (2015). Inflation perceptions and expectations in Sweden: Are media reports the missing link? Oxford Bulletin of Economics and Statistics, 77(5), 681-700.

[13] Hansen, L. P., Sargent, T. J. and Tallarini, T. D. (1999). Robust Permanent Income and Pricing. Review of Economic Studies, 66(4), 873-907.

[14] Jurado, K., Ludvigson, S. C., \& Ng, S. (2015). Measuring Uncertainty. American Economic Review, 105(3), 1177-1216.

[15] Karnizova, L., and Li, J. (2014). Economic policy uncertainty, financial markets and probability of US recessions. Economics Letters, 125(2), 261-265.

[16] Keynes, J. M. (2013). A treatise on probability. Courier Corporation.

[17] Kim, S. (2001). International transmission of U.S. monetary policy shocks: evidence from VAR's. Journal of Monetary Economics, 48(2), 339-372.

[18] Krugman, P (2012). The "Uncertainty" Scam, New York Times Blog, published: 22/10/2012. Available at: http://krugman.blogs.nytimes.com/ 2012/10/22/the-uncertainty-scam/ [Accessed: 29/7/2016]

[19] Krugman, P (2013). Phony Fear Factor, New York Times, issued: 9/8/2013, p. A19. Available at: http://www.nytimes.com/2013/08/09/opinion/krug man-phony-fear-factor.html?_r=0 [Accessed: 29/7/2016]

[20] Mackowiak, B. (2007). External shocks, U.S. monetary policy and macroeconomic fluctuations in emerging markets. Journal of Monetary Economics, 54, $2512-2530$.

[21] Mullainathan, S. and Shleifer, A. (2005). The market for news. American Economic Review, 95(4), 1031-53. DOI: 10.1257/0002828054825619

[22] Ramey, V. and Shapiro, M. (2001). Displaced capital: a study of aerospace plant closings. Journal of Political Economy, 109(5), 958-92.

[23] Smith A. (1952). An inquiry into the nature and causes of the wealth of nations. Great books of the Western world, v. 39. Chicago: Encyclopædia Britannica.

[24] Sorić, P. (2016). Consumer confidence as a GDP determinant in New EU Member States: a view from a time-varying perspective. Empirica (forthcoming), Available at: https://link.springer.com/article/10.1007/s10663-016- 
9360-4?wt_mc=Internal.Event.1.SEM.ArticleAuthorOnlineFirst [Accessed 05/12/17g., Available at: https://doi.org/10.1007/s10663-016-9360-4

[25] Stokey, N. L. (2013). Wait-and-See: Investment Options under Policy Uncertainty (No. w19630). National Bureau of Economic Research.

[26] Škrabić Perić, B., Sorić, P. (2017). A note on the "Economic Policy Uncertainty Index". Social Indicators Research (forthcoming), Available at: https:// link.springer.com/article/10.1007/s11205-017-1609-1 [Accessed 05/12/17]. Available at: https://doi.org/10.1007/s11205-017-1609-1.

[27] Toda, H.Y. and Yamamoto, T. (1995) Statistical inference in vector autoregressions with possibly integrated processes. Journal of Econometrics, 66(12), $225-250$. 